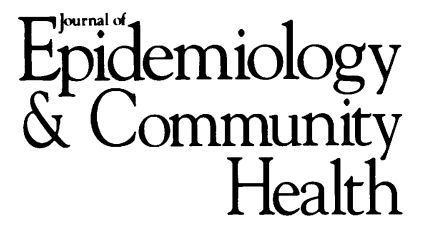

\title{
Editorial
}

\section{Abe Adelstein and the Manchester connection}

In taking up the Editorship of the Fournal of Epidemiology and Community Health I wish first to pay my respects to the memory of a friend and mentor and a great man in epidemiology.

Abe Adelstein, the eighth Chief Medical Statistician (from 1967 to 1981) in the succession of William Farr at the General Register Office in London, died on 18 October 1992.

Abe entered public health work when he took the DPH at Witwatersrand University in 1946 . He then worked as health officer in the South African Railways, becoming their Director of Research and Medical Statistics after 2 years at the London School of Hygiene, which included work as a research assistant for Donald Reid, Austin Bradford Hill, and Richard Doll. Abe returned permanently to Britain after 1960 and was Senior Lecturer in the Department of Social and Preventive Medicine in the University of Manchester from 1961 to 1967 before moving to London.

In the Manchester department established by Fraser Brockington and further developed by Alwyn Smith, which I now have the honour to head, Abe worked with Mervyn Susser and Zena Stein. Their epidemiological survey of mental health in Salford resulted inter alia in the writing of a special program for the Atlas computer. Abe wrote in the mid 1960s, "It seems clear that there will be widespread demand for this program because high speed computers make possible the analysis of complex data in a reasonable time and enable field workers to design surveys with multiple factors." His clarity and breadth of vision are clear.

In my time as Lecturer in Surgery with Ian McColl from 1970 to 1973 I moved from the operating theatre to the research laboratory and outwards to the casualty department and then to the community in South East London. This was followed by the opportunity to retrain in "social medicine" under Jerry Morris at the London School. I visited Donald Acheson's new medical school and department of community medicine in Southampton before I left surgery, and my first job after leaving the London School was a joint appointment with Donald and Abe.

The experience of 5 years working in university and civil service with these two mentors made for a fruitful and varied entry into a second career for me. Abe was a member of the interview panel for that job and they gave me a hard time. Abe said to me some time afterwards, "I knew you were better than you performed!" When I was leaving OPCS after 5 years and looking towards Hong Kong, I can remember talking with Abe over lunch about aspirations and ambitions. Abe said encouragingly, "What other people think about you is not so very important, is it?"

Others knew Abe much better than I did (and have written their tributes in the press and the weekly journals) but I recuunt these two personal stories as fond memories of the sort of man he was-perceptive and generous hearted to individuals, as well as concerned for the welfare of the people. $\mathrm{He}$ worked and wrote unassumingly and contributed, often with younger colleagues whom he was encouraging, not only to government publications but also to many journals including this one. We honour his memory.

From 1993 the editorship of the fournal of Epidemiology and Community Health moves to Manchester. I am pleased to be able to take over in a strong position developed by John Colley, and wish him well in his forthcoming retirement. I have an efficient and friendly local team with strong London support from the $B M F$ and an editorial board reconstituted to include colleagues from continental Europe.

Abe Adelstein's interests ranged from the health of railway workers in South Africa to the health and welfare of the whole population of England and Wales. This Journal will continue to promote both the study of and the improvement of the health of communities over a similarly wide area. With continued support from contributors and readers (special terms being offered to members of the Society for Social Medicine) I propose to emphasise health services research and development as a proper use of epidemiology, with the Journal contents in two main sections: analytical epidemiology (including but extending more widely than "risk-factor-ology") and the evaluation of health care, health services and other influences on the health of communities in Europe and worldwide.

STUART DONNAN

Editor

\section{Preventive medicine and the health of a nation}

Strategies for improving the health of a nation tend to evolve gradually from a varying mix of aetiological knowledge, perceptions of risk, public concern, and political will, and the development of more effective preventive medicine is arguably among the most difficult of strategic evolutions. Many countries are reviewing their notions of preventive medicine as applied to individuals and to the whole population, and in Britain the recent publication of Geoffrey Rose's book the
Strategy of preventive medicine and the government discussion document, The health of the nation, has stimulated debate on this topic. In this two part editorial strategies for prevention of cardiovascular and chronic respiratory diseases are discussed in the light of these publications. 